\title{
Effect of Si, Mn, Sn, and Cu on the Tempering Stages
}

\section{of $\mathbf{F e}-\mathbf{1 . 0} \% \mathrm{C}$ Alloys*}

\section{By Tetsu $\mathrm{OI}^{* *}$}

The effect of silicon on the tempering process has been extensively investigated by many authors. It seems authorized, therefore, that the start point of the stage 3 tempering is retarded. ${ }^{1-5)}$ These authors, however, used specimens containing more than $0.2 \%$ of silicon and there has not been reported how silicon of the amount as low as $0.2 \%$ or lower could affect the tempering spectrum. Moreover, another common alloying element, manganese, has not been taken notice of because this element is believed to have little effect on the tempering process. At least, manganese does not change the stage 3 tempering. ${ }^{5)}$

In addition to these common alloying elements just mentioned above, tin and copper often contaminate commercial carbon steels because these elements are hardly eliminated during steelmaking process. The effect of tin has already been investigated by the present author, ${ }^{6)}$ giving the result that this element alone does not affect the tempering spectrum up until the stage 3 when the amount does not exceed $0.18 \%$. The effect of this element with the addition of other elements, such as silicon and manganese, however, has not been reported. Moreover, the effect of copper, another undesirable element, has not been investigated.

The purpose of this experiment is to investigate how silicon, manganese, tin, and copper affect the temperature spectrum of tempering of $\mathrm{Fe}-1.0 \% \mathrm{C}$ steel when these element are added either independently or with each other. Silicon and manganese are, however, added with each other whenever these two elements are added. Chemical composition of the alloys investigated are listed in Table 1. These

Table 1. Chemical composition of the specimens (wt \%)

\begin{tabular}{c|ccccc}
\hline $\begin{array}{c}\text { Specimen } \\
\text { No. }\end{array}$ & C & Si & Mn & Sn & Cu \\
\hline 1 & 1.00 & - & - & - & - \\
2 & 1.00 & - & - & 0.079 & - \\
3 & 0.99 & - & - & - & 0.16 \\
4 & 1.00 & - & - & 0.110 & 0.16 \\
5 & 1.00 & 0.21 & 0.33 & - & - \\
6 & 1.00 & 0.21 & 0.33 & 0.07 & 0.20 \\
7 & 1.13 & 0.22 & 0.41 & - & - \\
8 & 1.13 & 0.24 & 0.41 & 0.08 & 0.27 \\
\hline
\end{tabular}

$\mathrm{Si}=0.1, \mathrm{Mn}=0.01, \mathrm{Sn}=0.01, \mathrm{Cu}=0.01$, when the figures are not shown.

Other impurities: $\mathrm{P}=0.005, \mathrm{~S}=0.01, \mathrm{As}=0.02, \mathrm{Sb}=0.01$, $\mathrm{Ni}=0.005, \mathrm{Gr}=0.01, \mathrm{~B}=0.001, \mathrm{~N}=0.0005, \mathrm{O}=0.001$, and $\mathrm{H}=0.00002$. alloys were melted in a magnesia crucible under low pressure argon atmosphere using re-electrolytic iron, electrode carbon, and metallic silicon, manganese, tin or copper as raw materials. The ingot was forged, rolled, and cold-drawn till $0.4 \mathrm{~mm}$ in diameter, with proper intermediate annealing, and finally subjected to spheroidization annealing giving diameter of cementite of 5 to $10 \mu$. Potential leads were spotwelded with proper gauge length to make the specimen compatible of resistivity measurement by means of usual potentiometric method.

Specimens were brine-quenched from $850^{\circ} \mathrm{C}$ and subjected to $20 \mathrm{deg}-10 \mathrm{~min}$ isochronal tempering from room temperature to $400^{\circ} \mathrm{C}$, resistivity being measured at each step in liquid nitrogen temperature. Typical tempering curves are shown in Fig. 1, where in case of pure $\mathrm{Fe}-\mathrm{C}$ alloy queched-in resistivity is $22 \mu \Omega \mathrm{cm}$ and decreases gradually as tempering temperature is raised, while in case of the alloy containing silcon, manganese and others (No.6) show quenched-in resistivity as high as $27 \mu \Omega \mathrm{cm}$ due to the fact that it contains larger amount of solute elements.

Let us then calculate the temperature derivatives for these curves shown in Fig. 1. The results are

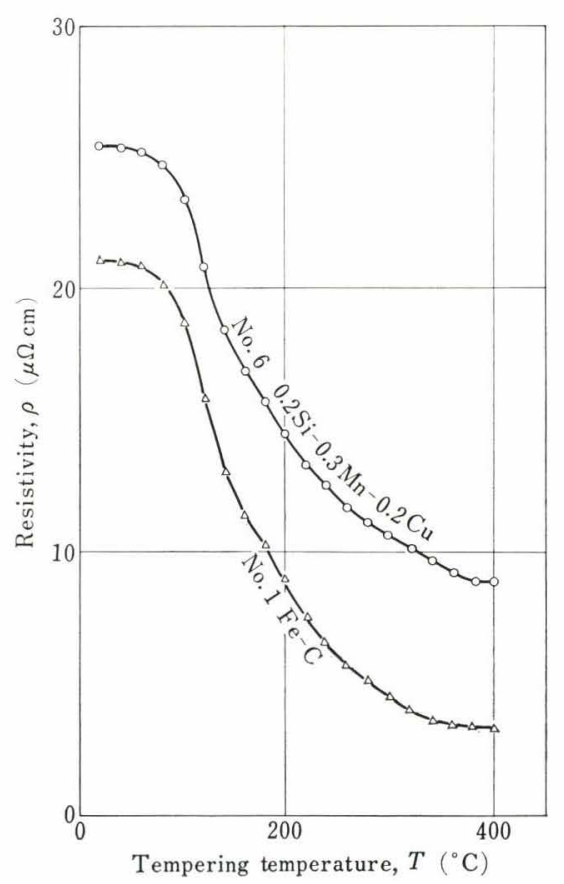

Fig. 1. Representative curves of the change of resistivity due to isochronal tempering by $20 \mathrm{deg}-10 \mathrm{~min}$

* Presented at the 66th JIM Meeting, April, 1970 in Tokyo. Manuscript received July 30, 1970.

** Central Research Laboratory, Hitachi, Ltd., Kokubunji, Tokyo 185. 


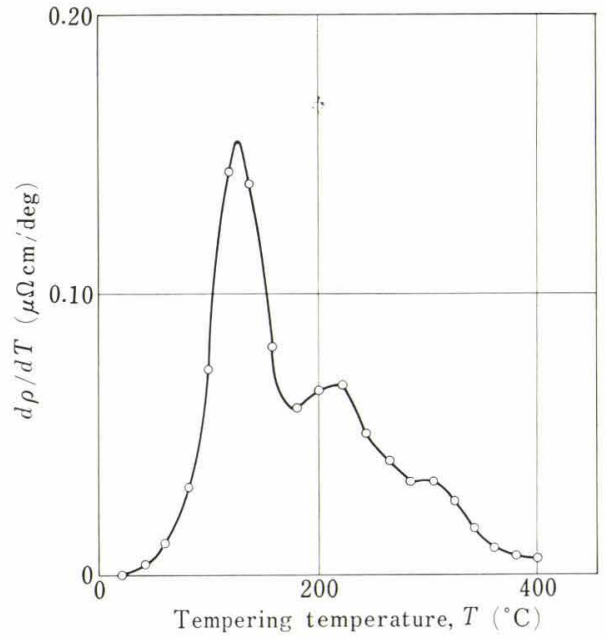

Fig. 2. Temperature derivative of the change of resistivity for pure $\mathrm{Fe}-\mathrm{C}$ alloy

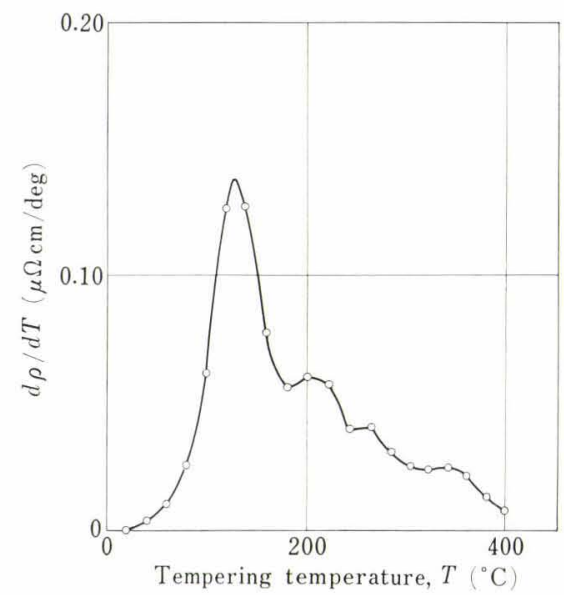

Fig. 3. Temperature derivative of the change of resistivity for $\mathrm{Fe}-\mathrm{C}-0.2 \% \mathrm{Si}-0.3 \% \mathrm{Mn}-0.2 \% \mathrm{Cu}$ alloy

shown in Figs. 2 and 3. The temperature spectrum of tempering for the pure $\mathrm{Fe}-\mathrm{C}$ alloy has three peaks as shown in Fig. 2 and these peaks can duly be attributed to the well-known three stages of tempering of high carbon steel, namely stage 1 (precipitation of $\varepsilon$ carbide), stage 2 (decomposition of retained austenite), and stage 3 (precipitation of cementite). Alloys containing tin and/or copper were found to show entirely the same trend as the pure $\mathrm{Fe}-\mathrm{C}$ alloy, although the experimental curves are not shown.

Quite different is the case in the alloys containing silicon and manganese where four peaks appear in the temperature spectrum in the temperature range between room temperature and $400^{\circ} \mathrm{C}$ as shown in Fig. 3 instead of three peaks in the same temperature range in case of pure $\mathrm{Fe}-\mathrm{C}$ alloys or alloys containing only tin and/or copper. These four peaks may be named those of stages $1,2 \mathrm{~A}, 2 \mathrm{~B}$, and 3 in sequence from lower temperature. The peak of stage 3 is shifted to higher temperature by about 30 degree. Owen has already found that $0.4 \% \mathrm{Si}$ retard stage $\left.3,{ }^{2}\right)$ but it must be noticed that silicon of the amount as low as only $0.2 \%$ still retard this stage. In addition the fact that silicon is rather unusual element as to retard stage 3 has to be pointed out. Such other familiar

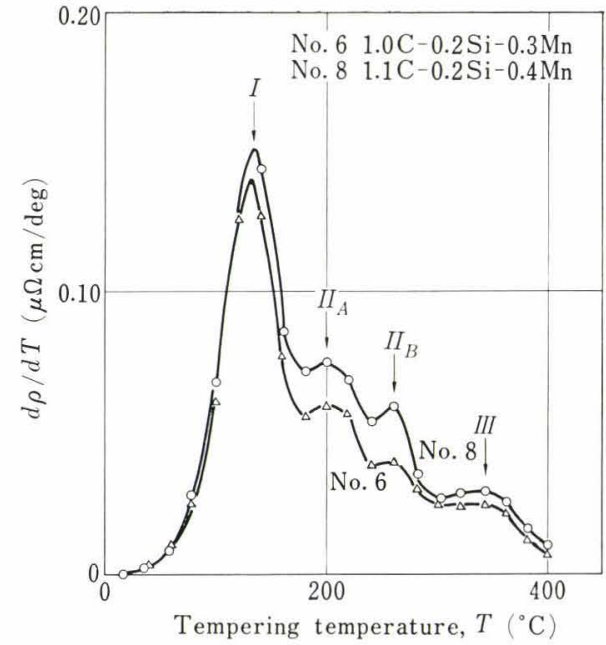

Fig. 4. Curves of temperature derivative, showing the growth of the peaks $I I_{\mathrm{A}}$ and $I I_{\mathrm{B}}$ as a result of the increase of manganese content

elements as manganese, nickel, chromium, molybdenum, vanadium, and cobalt do not have any effect of this kind and only arsenic is the one that has the same effect as silicon has.

Next is considered the stage 2 tempering. In Fig. 4 the increase of the height of the second and the third peaks due to the increase of manganese addition is demonstrated. Since manganese is known to be the typical austenite forming element, it can duly be assumed that these two peaks are attributed to the stage 2 tempering due to decomposition of retained austenite. Since pure $\mathrm{Fe}-\mathrm{C}$ alloy has only one peak attributable to stage 2, manganese has effect of split the stage 2 tempering, the reason being unknown.

It is not certain whether silicon has any effect to split the stage 2 peak as long as the result of this experiment is concerned. Another experiment has to be carried out to make certain of this problem. Referring to the other alloying elements investigated, tin and copper were found to have no additional effect of the tempering stages even if they are alloyed simultaneously.

In summary, manganese (or manganese plus silicon) split stage 2 peak while silicon of the amount as low as $0.2 \%$ retards stage 3 peak of the temperature spectrum of tempering of $\mathrm{Fe}-1.0 \% \mathrm{C}$ alloy. $0.1 \% \mathrm{Sn}$ and/or $0.2 \% \mathrm{Cu}$ have no effect on the tempering stages 1,2 , and 3 .

I am grateful to Drs. K. Ono and N. Nakamura of Hitachi Metals Ltd., and to Dr. H. Ohara of this laboratory for their helpful advice and encouragement.

\section{REFERENCES}

1) A. G. Alten and D. Payson: Trans. ASM, 45 (1953), 498.

2) W. S. Owen: Trans. ASM, 46 (1954), 812.

3) M. Ibaraki and T. Okumura: J. Japan Inst. Met., 19 (1955), 223, 226.

4) N. Yamanaka and K. Kusaka: Tetsu-to-Hagané, 40 (1954), 362.

5) A. S. Kenneford and T. Williams: J. Iron Steel Inst., 185 (1957), 467.

6) T. Oi : J. Japan Inst. Met., to be published. 